\title{
Spinal Osteoartritte Tedavi Yaklaşımları
}

\author{
Adem AKTÜRK ${ }^{*}$, Gamze KILIÇ ${ }^{* *}$, Emre ŞENOCAK ${ }^{* * *}$, M. Salih BARAN ${ }^{* * * * *}$
}

\section{$\ddot{O} \mathbf{z}$}

Amaç: Servikal bölge problemine sahip bireyler daha çok medikal yöntemler ile tedavi edilmeye çalışılmaktadır. Kullanılan ilaçların birçoğu, hastaların semptomlarını baskılama eğilimindedir. Yapacağımız bu çalışma ile hastalara uygulanan tedavi yöntemlerinin semptomlarda meydana getirdiği değişiklikler fiziki muayene yöntemleri ile kontrol edilecektir.

Yöntem: Çalışmaya 50 yaşın üstünde, 3 aydan daha uzun süredir boyun ağrısı çeken ve boyun eklem hareketlerinde kısıtlllık şikâyeti bulunan, radyolojik grafilerinde dejeneratif değişiklikler tespit edilen, Servikal spondiloartrit (SSA) tanısı almış toplam 60 kişi dahil edilmiştir. Daha önceden fraktür veya servikal bölgeyi içeren operasyonlar geçiren veya bir hastalığa bağlı olarak gelişen sekonder osteoartrit hastaları çalışmaya dahil edilmedi. Hastalara ayrıntılı olarak fizik ve nörolojik muayene testleri uygulandı. Postürü, servikal hareketleri, boyun çevresi muayenesini, derin tendon reflekslerini, duyu ve nörolojik muayeneleri kapsayan testler yapıldı. Bütün katılımcılara servikal distraksiyon, kompresyon, valsalva manevrası, vertebro-basiler provakasyon testleri uygulandı. Hastalar 2 tedavi grubuna ayrıldı. Birinci gruba 15 seans klasik fizik tedavi ajanları ile hastalara izometrik boyun egzersizleri ve izotonik kuvvetlendirme egzersizlerini içeren egzersiz programı uygulandı. İkinci gruba ise ilk gruptaki modalitelere ek olarak asemetasine $60 \mathrm{mg}$ (2x1 gün) ve tizanidin $2 \mathrm{mg}$ (2x1 gün) olarak verildi.

\section{Özgün Araştırma Makalesi (Original Research Article)}

Geliş / Received: 23.07.2019 \& Kabul / Accepted: 29.07.2019

* Dr. Öğr. Üyesi, İstanbul Gelişim Üniversitesi, Sağglık Hizmetleri Meslek Yüksekokulu, Fizyoterapi Programı, İstanbul, Türkiye, E-posta: draakturk@gmail.com ORCID ID https://orcid.org/0000-0002-2487-5720

*** Uzman Fizyoterapist, İstanbul Özel Safa Hastanesi, Fizyoterapi ve Rehabilitasyon Polikliniği, İstanbul, Türkiye, E-posta: fztgamzekilic@gmail.com ORCID ID https://orcid.org/0000-00023687-1014

**** Arş. Gör., Marmara Üniversitesi, Sağlık Bilimleri Fakültesi, Fizyoterapi ve Rehabilitasyon Bölümü, İstanbul, Türkiye, E-posta: emre.senocak@windowslive.com ORCID ID https://orcid.org/0000-0003-3677-9813 **** Dr. Öğr. Üyesi, İstanbul Gelişim Üniversitesi, Sağlık Hizmetleri Meslek Yüksekokulu, Ameliyathane Hizmetleri Programı, İstanbul, Türkiye, E-posta: drmsb@gmail.com ORCID ID https://orcid.org/0000-0002-9979-2081 
Bulgular: Cinsiyet dağılımına bakıldığında katılımcıların 63’ü (\%70) kadın, 27’si (\%30) erkekti. Hastaların yaş ortalaması ise $62,81 \pm 6,98$ olarak tespit edildi. Fizik tedavi ve medikal tedavi alan tedavi grubun tüm parametrelerde istatistiksel olarak anlaml sonuçlar elde edilmiştir. Fizik tedavi grubunda ise tedavi öncesine göre kas spazmı ve boyun fleksiyonunda anlamlı derecede değişiklikler tespit edildi. Bu hastalarda boyun ekstansiyonu, duyu muayenesi servikal kompresyon ve vertebrobaziler provakasyon testlerinde değişiklik saptanmadı.

Sonuç: Çalışma grubumuzda; ilaç tedavisi ve fizyoterapi yöntemlerinin beraber uygulandığı grubumuzda boyun hareketlerinde diğer gruplara oranla daha fazla artış gözlemlenmiştir. Ayrıca boyun bölgesine yönelik servikal testlerde de olumlu iyileşmeler gözlemlenmiştir. Çalışmanın sonuçlarına göre; medikal tedavi ile birlikte alınan fizyoterapi modaliteleri uygulandığında klinik olarak daha anlamlı sonuçlar elde edilmektedir.

Anahtar Sözcükler: Servikal osteoartrit, vertebrobaziler arter testi, servikal spazm.

\title{
Treatment Approaches for Spinal Osteoarthritis
}

\begin{abstract}
Aim: Generally, medical interventions are used for cervical region's treatment. Most of the medicines are used for repress the symptoms. In this study; we will have checked the alterations with a physical examination after the different treatment methods which applied to patients.

Method: In this study; we included 60 subjects diagnosed with SSA. Inclusion criteria; over the 50-y, cervical region pain and limitation of cervical joint movement for more than 3 months, degenerative changing radiological screens. Exclusion criteria; cervical fracture, cervical region's surgery, seconder osteoarthritis after different disease. Physical and neurological tests as posture assessment, cervical movements, deep tendon reflexes, sense tests were applied. Also; cervical distraction, compression, Valsalva maneuver, vertebrobasilar provocation were applied. Patients divided to 2 groups. To group 1; conventional physical therapy interventions, isometric neck exercises, and isotonic strength exercise programs were applied. To Group 2; conventional physical therapy interventions, isometric neck exercises, isotonic strength exercise program and asemetasine $60 \mathrm{mg}$ (2x1 day), tizanidine $2 \mathrm{mg}$ (2x1 day) were applied.
\end{abstract}

Findings: In this study; there are 63 (\%70) women, 27 (\%30) men. Subject's age average is $62,81 \pm 6,98$. Group 2 have significantly differences in all parameters. Group 1 have significant differences just in muscle spasm and neck flexion movement parameters. There is no significant differences in neck extension, sense examination, cervical compression, and vertebrobasilarr provocation tests. 
Conclusion: While physical therapy interventions and medical treatment are applied together, there is a further increase in neck movements compared with other groups. Combined treatment method is more effective clinically.

Keywords: Cervical osteoarthritis, vertebrobasilar artery test, cervical spasm.

\section{Giriş}

Servikal spondiloartrit (SSA), servikal intervertebral disklerde başlayan ve çevredeki kemik ve yumuşak dokularda da değişikliğe yol açan dejeneratif bir hastalıktır ${ }^{1}$. Bu terimin içerisine intervertebral diskteki dejeneratif değişiklikler, vertebra uzantılarında osteofit, faset eklemlerde hipertrofi gibi değişiklikler de girer. Hastalığın semptomları arasında boyun tutukluğu, kas spazmı, hareket kısıtlılığı, lokal ağrı gösterilebilir²,3. Özellikle geceleri olmak üzere, boynun sabit pozisyonunda tutulduğu durumlarda uyuşma ve karıncalanma şikâyetlerinde artış meydana gelmektedir4. Tedavi parametreleri olarak klasik fizik tedavi ajanları ve ilaçlar kullanılmaktadır.

Çalışmamızda, uygulanacak tedavi yöntemlerinin fiziksel muayene semptomlarında oluşturacağı değişiklikler incelenecektir. Bu sebeple çalışmamızın amacı; konservatif tedavi yöntemleri ve buna ek uygulanan medikal tedavinin SSA'lı hastaların fiziksel muayene semptomları ile ağrı parametreleri üzerine etkisinin incelenmesi olarak belirlenmiştir.

\section{Gereç ve Yöntem}

Çalışmaya 50 yaş ve üzerinde, 3 aydan daha uzun süredir boyun ağrısı çeken ve boyun eklem hareketlerinde kısıtlılık şikâyeti bulunan, radyolojik grafilerinde dejeneratif değişiklikler tespit edilen, SSA tanısı almış toplam 6o kişi dâhil edilmiştir. Daha önceden fraktür veya servikal bölgeyi içeren operasyonlar geçiren veya bir hastalığa bağlı olarak gelişen sekonder osteoartrit hastaları çalışmaya dâhil edilmemiştir.

Kliniğe başvuran hastalara ayrıntılı olarak fizik ve nörolojik muayene testleri uygulandı. Postür, servikal hareketler, boyun çevresi muayenesi, derin tendon refleksleri, duyu ve nörolojik muayeneleri kapsayan testler yapıldı. Bütün katılımcılara servikal distraksiyon, kompresyon, valsalva manevrası, vertebrobaziler provakasyon testleri uygulandı. 
Hastalar 2 tedavi grubuna ayrıldı. Birinci gruba 15 seans klasik fizik tedavi ajanları uygulandı. Bu ajanları; 7 dakika boyunca ultrason (1,5 Watt/ $\left.\mathrm{cm}^{2}\right), 15$ dakika boyunca infraruj, 10 dakika boyunca vakum enterferansiyel akım (90-100 Hz) oluşturdu. Terapötik ajanlardan sonra hastalara izometrik boyun egzersizleri ile izotonik kuvvetlendirme egzersizlerini içeren egzersiz programı uygulandı. Bu programlar bir fizyoterapist tarafindan uygulanıp takip edildi. İkinci gruba ise ilk gruptaki modalitelere ek olarak asemetasine $60 \mathrm{mg}$ (2x1 gün) ve tizanidin $2 \mathrm{mg}$ (2x1 gün) olarak verildi.

Servikal Spazm: Servikal bölge yumuşak doku palpasyonu ile bölgede gerginlik hissinin değerlendirici tarafından değerlendirilmesiyle karar verilir. Spazm olan bireylere “1”, olmayanlara ise “o” puan verilir.

Servikal Bölge Eklem Hareket Açıklı̆ğ: Universal gonyometre kullanılarak boynun fleksiyon ve ekstansiyon yönündeki hareket açıklığında limitasyon olup olmadığı test edilir. Eklem hareket açıklığı azalan bireylere "1", azalmayanlara ise "o" puan verilir.

Duyu Testi: Duyu muayenesinde hafif dokunma duyusu pamukla, ağrı duyusu toplu iğneyle, derin duyu ise pozisyon hissiyle değerlendirildi. Duyu kaybı olan bireylere "1", olmayanlara ise "o" puan verilir.

Vertebrobaziler Provakasyon Testi: Hasta sırt üstü yatarken baş ve boynu klinisyen tarafından pasif olarak ekstansiyon ile birlikte lateral fleksiyon ve rotasyon pozisyonuna götürülür; hastanın gözleri açıtır ve bu pozisyonda 30 saniye beklenir. Baş dönmesi, nistagmus, bulantı, kulak çınlaması gibi semptomlar oluşursa test pozitif olarak kabul edilir5. Test pozitif olan bireylere "1", olmayanlara ise "o" puan verilir.

Servikal Kompresyon Testi: Servikal kompresyon testi'nde (Spurling testi) hastanın başı, ağrıyan tarafa doğru döndürülmüş bir biçimde pozisyonlanıp, yukarıdan aşağıya doğru baskı uygulanarak yapılır. Baskı uygulandıktan sonra şikâyetlerde artma

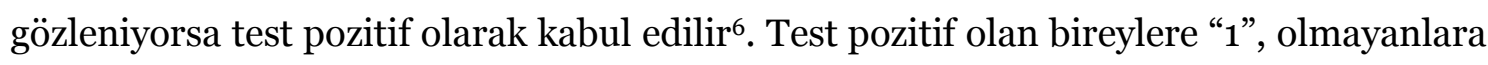
ise "o" puan verilir. 


\section{Ístatistik Analiz}

Çalışmamızda toplanan verilerin analizinde SPSS 18.0 istatistiksel analiz programı kullanılmıştır. Ölçümle belirtilen değişkenler için tanımlayıcı istatistikler ortalama ve standart sapma değerleri kullanılmıştır. Gruplar arası farklılı̆̆ın belirlenmesinde tedavi öncesi ve sonrası farkların değerlendirilebilmesi için ise eşleşmiş gruplarda $t$ testi kullanılmıştır.

\section{Bulgular}

$\mathrm{Bu}$ çalışma, Servikal spondiloartropatili hastalara uygulanan farklı tedavi modalitelerinin sonrasında fiziki muayene testlerinde meydana gelen değişiklikleri belirlemek için yapıldı.

Cinsiyet dağılımına bakıldığında katılımcıların 63’ü (\%70) kadın, 27'si (\%30) erkekti. Hastaların yaş ortalaması ise $62,81 \pm 6,98$ olarak tespit edildi. Fizik tedavi ve medikal tedavi alan tedavi grubunda tüm parametrelerde istatistiksel olarak anlamlı sonuçlar elde edilmiştir (Tablo 1).

Tablo 1: Fizik tedavi ve medikal tedavi alan grubun öncesi-sonrası değerlendirilmesi

\begin{tabular}{|l|l|l|}
\hline & $\begin{array}{l}\text { Ortalama } \pm \text { Standart } \\
\text { Sapma }\end{array}$ & P değeri \\
\hline Servikal Spazm & $0.63 \pm 0.49$ & 0.001 \\
\hline Fleksiyon Eklem Hareketi & $0.26 \pm 0.58$ & 0.018 \\
\hline $\begin{array}{l}\text { Ekstansiyon Eklem } \\
\text { Hareketi }\end{array}$ & $0.36 \pm 0.76$ & 0.014 \\
\hline Duyu Muayenesi & $0.20 \pm 0.40$ & 0.012 \\
\hline $\begin{array}{l}\text { Vertebrobaziler } \\
\text { Provakasyon }\end{array}$ & $0.56 \pm 0.20$ & 0.034 \\
\hline Kompresyon Testi & $0.66 \pm 0.20$ & 0.601 \\
\hline
\end{tabular}

Medikal tedavi grubunda ise tedavi öncesine göre kas spazmı ve boyun fleksiyonunda anlamlı derecede değişiklikler tespit edildi. Bu hastalarda boyun ekstansiyonu, duyu 
muayenesi servikal kompresyon ve vertebrobaziler provakasyon testlerinde değişiklik saptanmadı (Tablo 2).

Tablo 2: Medikal tedavi alan grubun öncesi-sonrası değerlendirilmesi

\begin{tabular}{|l|l|l|}
\hline & $\begin{array}{l}\text { Ortalama } \pm \text { Standart } \\
\text { Sapma }\end{array}$ & P değeri \\
\hline Servikal Spazm & $0.40 \pm 0.49$ & 0.001 \\
\hline Fleksiyon Eklem Hareketi & $0.36 \pm 0.49$ & 0.001 \\
\hline $\begin{array}{l}\text { Ekstansiyon Eklem } \\
\text { Hareketi }\end{array}$ & $0.33 \pm 0.19$ & 0.926 \\
\hline Duyu Muayenesi & $0.10 \pm 0.30$ & 0.083 \\
\hline $\begin{array}{l}\text { Vertebrobaziler } \\
\text { Provakasyon }\end{array}$ & $0.10 \pm 0.30$ & 0.083 \\
\hline Kompresyon Testi & $0.66 \pm 0.25$ & 0.161 \\
\hline
\end{tabular}

Tedavi sonrasında hastaların karşılaştıkları yan etkiler sorgulandı. Fizik tedavi modalitelerine ek olarak ilaç kullanan gruptaki 19 birey herhangi bir yan etki ile karşılaşmamışken, 11 birey gastroinstestinal sistem (GIS) problemleri ile karşılaştı. Bu sonuca benzer olarak sadece ilaç kullanan grupta ise 24 kişi herhangi bir yan etki ile karşılaşmamışken, 6 bireyde GIS şikâyetleri görüldü. Ayrıca tedavi sonrası azalan şikâyetler açısından bakıldığında kontrol grubunda 29 kişinin şikâyetlerinde azalma olmamışken sadece 1 kişide boyun ve omuz ağrısının geçtiği gözlendi. Klasik fizik tedavi ve medikal tedavinin birlikte uygulandığı gruptaki bireylerin tamamında fiziksel şikâyetlerde azalma gözlendi. Bu hastaların 21’i boyun ağrısında azalma olduğunu bildirirken, 7’si boyun hareketlerinde artış olduğunu belirtti. Diğer 2 kişide ise tutukluk ve kollara yayılan uyuşma semptomlarında azalma olduğu kaydedildi.

\section{Tartışma}

Servikal spondilartrit; korpus, lamina, disk, faset gibi servikal kolonu meydana getiren yapıların dejenerasyonu ve bunun sonucu ortaya çıkan osteoartritik ve nörovasküler bozuklukların tümünü kapsayan genel bir klinik terimdir7. Türk popülasyonunda 
genellikle servikal spondilartrit ve buna bağlı olarak ağrı gelişimi genellikle ev hanımlarında görülmektedir. Esenyurt ve arkadaşlarının yaptıkları çalışmada spondilartrite bağlı baş ağrısı olan kadın hastalar erkek hastalara göre altı kat fazlaydı. Bizim çalışmamızda da kadın örneklemler erkeklere oranla fazlaydı.

SSA'da temel hedef ağrı semptomunun azaltılmasıdır. Bu sebeple tedavide non-steroid antiinflamatuar ilaçların (NSAİD) kullanımı önemli yer tutar ${ }^{8,9}$. NSAİD ve miyorelaksanlar sayesinde hastaların ağrıları azalabilmekte buna bağlı olarak eklem hareket açıklıkları artabilmektedir. Ancak NSAİD kullanımı konusunda farklı görüşler vardır. Rashad ve arkadaşlarının yaptıkları çalışmada NSAİD ilaçların osteoartritlerin ilerlemesini hızlandırdığını, bunu da vazodilatör prostoglandinlerin sentezini azaltıp eklem perfüzyonunu kötü yönde etkileyerek yaptığından söz ekmektedir. Buna karşın Calin yaptığı çalışmada; NSAİD ilaçların kıkırdak ve proteoglikan sentezi üzerinde herhangi bir olumsuz etkileri varsa bile; bunların söz konusu ilaçların proteolitik enzimleri inhibisyona uğratmak şeklindeki yararlı etkilerinin yanında önemini kaybettiğini bildirmektedir.

NSAİD ilaçların sistemik yolla verilmeleri her zaman hastalara aynı şekilde olumlu etki olarak geri dönmemektedir. Bizim çalışmamızda da toplamda 17 kişide GIS problemleri görüldü.

Dejeneratif SSA'da fizik tedavi modaliteleri eskiden beri kullanılmaktadır. Bu süreçte kaplıca, balneoterapi gibi tedaviler daha çok kastaki trofik bozuklukların giderilmesi, ağrının azaltılması için kullanılırken, medikal tedaviler ise daha çok ağrının ağrı-spazm döngüsünü kırmaya yöneliktir. Özellikle sıcak uygulamaları kas spazmının çözülmesine büyük ölçüde yardım etmektedir ${ }^{10}$. Çalışmamızda kullandığımız terapötik ultrason yüzeyel dokularda fazla ısınma yapmadan derin doku ve kasları ısıtır. Uygulandığı bölgede kan dolaşımını ve metabolizmayı artırarak, analjezik, spazmolitik tesir gösterir. Ultrason etkisi ile perferik dolaşım artıp sinir uçlarında ağrı eşiği yükselirken, enterferansiyel akım ile kas tonusu ve beslenmesi düzenlenir.

Çalışma grubumuzda; ilaç tedavisi ve fizyoterapi yöntemlerinin beraber uygulandığı grubumuzda boyun hareketlerinde dĭ̆er gruplara oranla daha fazla artış gözlemlenmiştir. Ayrıca boyun bölgesine yönelik servikal testlerde de olumlu iyileşmeler gözlemlenmiştir. 


\section{Sonuç}

SSA tanısı almış hastalara uygulanan tedavi yöntemlerinde medikal tedavi ve fizik tedavi yöntemi istatistiksel olarak anlamlı derecede iyileşme göstermiştir. Kontrol grubu hastaları ise sadece kas spazmı ve boyun fleksiyonunda anlamlı derecede değişiklikler gösterilmiştir. Her üç hasta grubunun tedavi öncesi ve sonrası ağrıları değerlendirildiğinde, kontrol grubunda ağrıda değişiklik olmazken, diğer iki grupta ağrı da belirgin derecede bir azalma mevcuttur. Ayrı ayrı uygulanan medikal tedavi ve fizik tedavi modaliteleri birlikte uygulandığında daha yüksek seviyede anlamlı iyileşme gösterilmiştir. SSA tanısı almış hastalara uygulanan fizik tedavi ve medikal tedavi kombinasyonunda VAS, postür, servikal hareketler ve nörolojik testlerde anlaml iyileşme tespit edilmiştir. Yan etkiler olarak değerlendirildiğinde medikal tedavi alan grupta yan etki şikâyeti daha fazla gözlenmiştir.

\section{KAYNAKLAR}

1. Lestini F, Wiesel W. The pathogenesis of cervical spondylosis. Clinical Orthopaedics and Related Research. 1989;(239):69-93.

2. Onel D. Romatizmal Hastalıklar. 1. Basım. İstanbul: Atlas Tıp Kitapevi; 1992.

3. Sengir O. Omurga Artrozu. In: Tuna N, ed. Romatizmal Hastalıklar. Ankara: Hacettepe Taş Kitapçılık Ltd. Şti; 1982;562,586.

4. Garfin SR, Herkowitz HN. The orthopedic clinic of North America. The Degenerative Neck. Philadelphia: WB Saunders Company, 1992;23(3):369-515.

5. Cyriax H, Cyriax P. Cyriax's Illustrated Manual of Orthopaedic Medicine. Elsevier Health Sciences; 1996.

6. Nordin M, Carragee J, Hogg-Johnson S, et al. Assessment of neck pain and its associated disorders: results of the bone and joint decade 2000-2010 task force on neck pain and its associated disorders. Journal of Manipulative and Physiological Therapeutics. 2009;32(2):117-140.

7. Onel D. Romatizmal Hastalkklar. 1. Basım. İstanbul: Atlas ofset; 1987. 
8. Kenneth KN. Neck pain. Textbook of Rheumatology. 3th. Philedelphia, Sounders Co, 1989;471-489.

9. Oğuz H. Romatizmal Ağrlar. 1. Basım. Konya: Atlas Tıp Kitapevi; 1992.

10. Kayhan Ö. Diatermi ve Yüzeysel Sıcak-Soğuk tedavileri. In: Nejdet T, çeviri ed. Krausen's Fizik Tedavi ve Rehabilitasyon El Kitabı. 3. Basım. İstanbul: Nobel Tip Kitapevi; 1988. 